\title{
Inhalt von Eusebius Band I.
}

\section{Einleitung.}

Seite

A. Die Handschriften . . . . . . . . . . . . . . . . . . . IX

B. Die indirekte Überlieferung . . . . . . . . . . . . . . XX XX

C. Die Selbstcitate des Eusebius . . . . . . . . . . . . XXVIII

D. Die Ausgaben . . . . . . . . . . . . . . . . . . . . XXXIX

E. Zweck und Charakter der Schrift „Über das Leben Constantins“ . XLV

F. Disposition der Schrift „Ūber das Leben Constantins" nebst einigen

Bemerkungen . . . . . . . . . . . . . . . . . . L LIII

G. Über die Verordnungen und Briefe Constantins . . . . . . . LXVI

H. Die religiöse Anschauung Constantins auf Grund seiner eigenen Schreiben . . . . . . . . . . . . . . . . . . . . . . LXXXIII

I. Die Rede an die heilige Versammlung . . . . . . . . . . . XCI

K. Die Capitelindices . . . . . . . . . . . . . . . . . . CIII

L. Die Tricennatsrede an Constantin. . . . . . . . . . . . . CIV

Schlusswort des Herausgebers. . . . . . . . . . . . . . CVI

Verzeichnis der Abkürzungen . . . . . . . . . . . . . . CVIII

Text.

A. Uber das Leben Constantins . . . . . . . . . . . . . . 1

B. Constantins Rede an die heilige Versammlung . . . . . 149

C. Tricennatsrede an Constantin . . . . . . . . . . . . . 193

\section{Register.}

I. Stellen register.

Altes 'T'estament . . . . . . . . . . . . . . . . . 263

Neues Testament . . . . . . . . . . . . . . . . 263

Kirchliche Schriftsteller . . . . . . . . . . . . . . . . . . 264

Nicht-kirchliche Schriftsteller . . . . . . . . . . . . 265

II. Namen register . . . . . . . . . . . . . . . . . . . 266

III. Wort- und Sachregister . . . . . . . . . . . . . . . 270

Nachträge und Berichtigungen . . . . . . . . . . . . 356 
